\title{
Non-opioid anesthetic drug abuse among anesthesia care providers: a narrative review
}

\section{L'abus de médicaments anesthésiques non opioïdes parmi le personnel d'anesthésie: un compte rendu narratif}

\author{
Alix Zuleta-Alarcón, MD · John C. Coffman, MD $\cdot$ Suren Soghomonyan, MD, PhD • \\ Thomas J. Papadimos, MD • Sergio D. Bergese, MD • Kenneth R. Moran, MD
}

Received: 15 October 2015/Revised: 19 March 2016/Accepted: 5 July 2016/Published online: 28 July 2016

(C) Canadian Anesthesiologists' Society 2016

\begin{abstract}
Purpose The objective of this narrative review is to provide an overview of the problem of non-opioid anesthetic drug abuse among anesthesia care providers (ACPs) and to describe current approaches to screening, therapy, and rehabilitation of ACPs suffering from non-opioid anesthetic drug abuse.

Source We first performed a search of all literature available on PubMed prior to April 11, 2016. The search was limited to articles published in Spanish and English, and the following key words were used: anesthesiology, anesthesia personnel, AND substance-related disorders. We also searched Ovid MEDLINE ${ }^{\circledR}$ databases from 1946-April 11, 2016 using the following search terms: anesthesiology OR anesthesia, OR nurse anesthetist OR anesthesia care provider $O R$ perioperative nursing $A N D$ substance-related disorders.

Principal findings Despite an increased awareness of drug abuse among ACPs and improvements in preventive measures, the problem of non-opioid anesthetic drug abuse
\end{abstract}

A. Zuleta-Alarcón, MD · J. C. Coffman, MD .

S. Soghomonyan, MD, PhD · S. D. Bergese, MD .

K. R. Moran, MD (ه)

Department of Anesthesiology, The Ohio State University

Wexner Medical Center, Doan Hall N 411, 410 W 10th Ave., Columbus, OH 43210, USA

e-mail: Kenneth.Moran@osumc.edu

\section{T. J. Papadimos, MD}

Department of Anesthesiology, University of Toledo College of Medicine and Life Sciences, Toledo, $\mathrm{OH} 43614$, USA

S. D. Bergese, MD

Department of Neurological Surgery, The Ohio State University Wexner Medical Center, Columbus, OH 43210, USA remains significant. While opioids are the most commonly abused anesthesia medications among ACPs, the abuse of non-opioid anesthetics is a significant cause of morbidity, mortality, and professional demise.

Conclusion Early detection, effective therapy, and long-term follow-up help ACPs cope more effectively with the problem and, when possible, resume their professional activities. There is insufficient evidence to determine the ability of ACPs to return safely to anesthesia practice after rehabilitation, though awareness of the issue and ongoing treatment are necessary to minimize patient risk from potentially related clinical errors.

\section{Résumé}

Objectif L'objectif de ce compte rendu est de présenter une vue d'ensemble du problème d'abus de médicaments anesthésiques non opiö̈des parmi le personnel d'anesthésie et de décrire les approches de dépistage, de traitement et de réhabilitation actuellement à la disposition du personnel d'anesthésie souffrant d'un abus de médicaments anesthésiques non opioüdes.

Source Nous avons commencé par réaliser une recherche de toute la littérature disponible sur PubMed avant le 11 avril 2016. La recherche se limitait aux articles publiés en espagnol et en anglais, et les mots clés suivants ont été utilisés: anesthésiologie, personnel d'anesthésie, ET troubles liés à l'abus de substance. Nous avons également effectué une recherche dans les bases de données Ovid MEDLINE ${ }^{\circledR}$ entre 1946 et le 11 avril 2016 à l'aide des termes de recherche suivants: anesthésiologie OU anesthésie, $O U$ infirmière anesthésiste OU personnel d'anesthésie OU soins infirmiers périopératoires ET troubles liés à l'abus de substances (soit: 'anesthesiology' ou 'anesthesia', ou 'nurse 
anesthetist' ou 'anesthesia care provider' ou 'perioperative nursing' et 'substance-related disorders').

Constatations principales Malgré une meilleure prise de conscience de l'abus de médicaments parmi le personnel d'anesthésie et les progrès en matière de mesures préventives, le problème qu'est l'abus de médicaments anesthésiques non opioïdes demeure considérable. Bien que les opioïdes soit les médicaments les plus fréquemment rencontrés dans les problèmes d'abus de médicaments anesthésiques chez le personnel d'anesthésie, l'abus de médicaments anesthésiques non opiö̈des constitue néanmoins une importante cause de morbidité, de mortalité et de terminaison de carrière.

Conclusion Le dépistage précoce, un traitement efficace et un suivi à long terme peuvent aider le personnel d'anesthésie à mieux gérer le problème et, lorsque cela est possible, reprendre leurs activités professionnelles. Les données probantes ne sont pas suffisantes pour attester que le personnel d'anesthésie peut revenir en toute sécurité à la pratique de l'anesthésie après réhabilitation, mais la prise de conscience du problème et un traitement continu sont nécessaires afin de minimiser le risque encouru par les patients d'erreurs cliniques potentiellement liées à ces abus.

Substance abuse among healthcare providers represents a serious problem that requires better understanding and continued investigation into its etiology, prevention, effective interventions, rehabilitation, and impact on patient safety. An estimated 10-15\% of physicians may become dependent on a substance at some time during their careers. ${ }^{1-3}$ While alcohol is the most commonly abused substance among physicians, ${ }^{1,3-6}$ the estimated incidence of dependency on other substances is $1-2 \% .^{1}$

Managing stressful work situations has been reported to contribute to substance abuse among physicians. ${ }^{7}$ It has been suggested that anesthesia providers are at increased risk for substance abuse relative to other medical specialties as a result of high levels of work-related stress, easier access to controlled substances, chronic exposure to trace quantities of addictive substances, and a variety of other potential contributing factors. ${ }^{8,9}$ Additionally, previous reports have indicated that anesthesiologists are overrepresented in drug treatment programs relative to their proportion among medical specialties and are more likely to abuse substances with a higher risk of relapse..$^{2,10,11}$ In addition to anesthesiology, other specialties, such as family medicine, internal medicine, and surgery, are overrepresented when compared with obstetrics and gynecology or pediatrics. ${ }^{2,10,12}$

Among anesthesiologists, the incidence of abuse of anesthetic drugs has been reported to be $1.0 \%$ among faculty and $1.6 \%$ among residents. ${ }^{1}$ Traditionally, opioids have been the most commonly abused anesthesia medication by anesthesia care providers (ACPs). ${ }^{1,9,13}$ Previous reports have documented opioids as the substances abused in $62 \%{ }^{9}$ and $66 \%{ }^{13}$ of cases. Nevertheless, non-opioid anesthesia medications also represent a significant source of abuse and are a potentially underappreciated cause of morbidity, mortality, and professional demise among ACPs.

Recently, Warner et al. performed a comprehensive retrospective investigation of substance use disorders among anesthesiology residents in the United States. The authors reported that 384 of 44,612 $(0.86 \%)$ residents trained from 1975-2009 developed a confirmed substance abuse disorder during their training. ${ }^{9}$ While opioids were the most commonly abused substances in this report (62\% of cases), non-opioid anesthetic abuse was cited in $19 \%$ of cases. ${ }^{9}$ A recent retrospective survey among ACPs in Australia and New Zealand reported that propofol was the most commonly abused substance (41\%), followed by opiates $(32 \%)$, alcohol $(27 \%)$, benzodiazepines $(16 \%)$, and inhalational agents $(5 \%){ }^{14}$ These results differed from the previous ten-year survey results. At that time, ACPs most commonly abused opioids $(66 \%)$, followed by induction agents $(20 \%)$, benzodiazepines $(5 \%)$, and inhalation agents $(5 \%) .^{13}$

The purpose of this narrative review is to discuss the available literature on ACP abuse of non-opioid medications commonly used in anesthesia practice, including propofol, inhalational anesthetics, ketamine, and benzodiazepines. This review also addresses the triggering mechanisms of substance abuse, its prevalence among ACPs, clinical manifestations, treatment options, prognosis, and the impact on career development and patient safety.

In order to accomplish this objective, we performed a search of all literature available on PubMed prior to April 11, 2016. The search was limited to human articles published in Spanish and English, and the following medical subject headings, terms, and keywords were used: anesthesiology, anesthesia personnel, AND substance-related disorders. We also searched Ovid MEDLINE ${ }^{\circledR}$ from 1946-April 11, 2016 using the following search terms: anesthesiology $O R$ anesthesia, $O R$ nurse anesthetist $O R$ anesthesia care provider $O R$ perioperative nursing AND substance-related disorders. We also included publications identified in our review of the references for these articles. We included case reports, reviews, and original articles that addressed consumption of non-opioid anesthetic agents (Table), but we excluded papers that assessed only the consumption of opioids, alcohol, marijuana, cocaine, amphetamines, or hallucinogens (Figure).

\section{Mechanisms of addiction}

Substance abuse is characterized by persistent and clinically significant consequences related to the repeated use of psychotropic drugs or other neurotropic substances. ${ }^{15}$ 


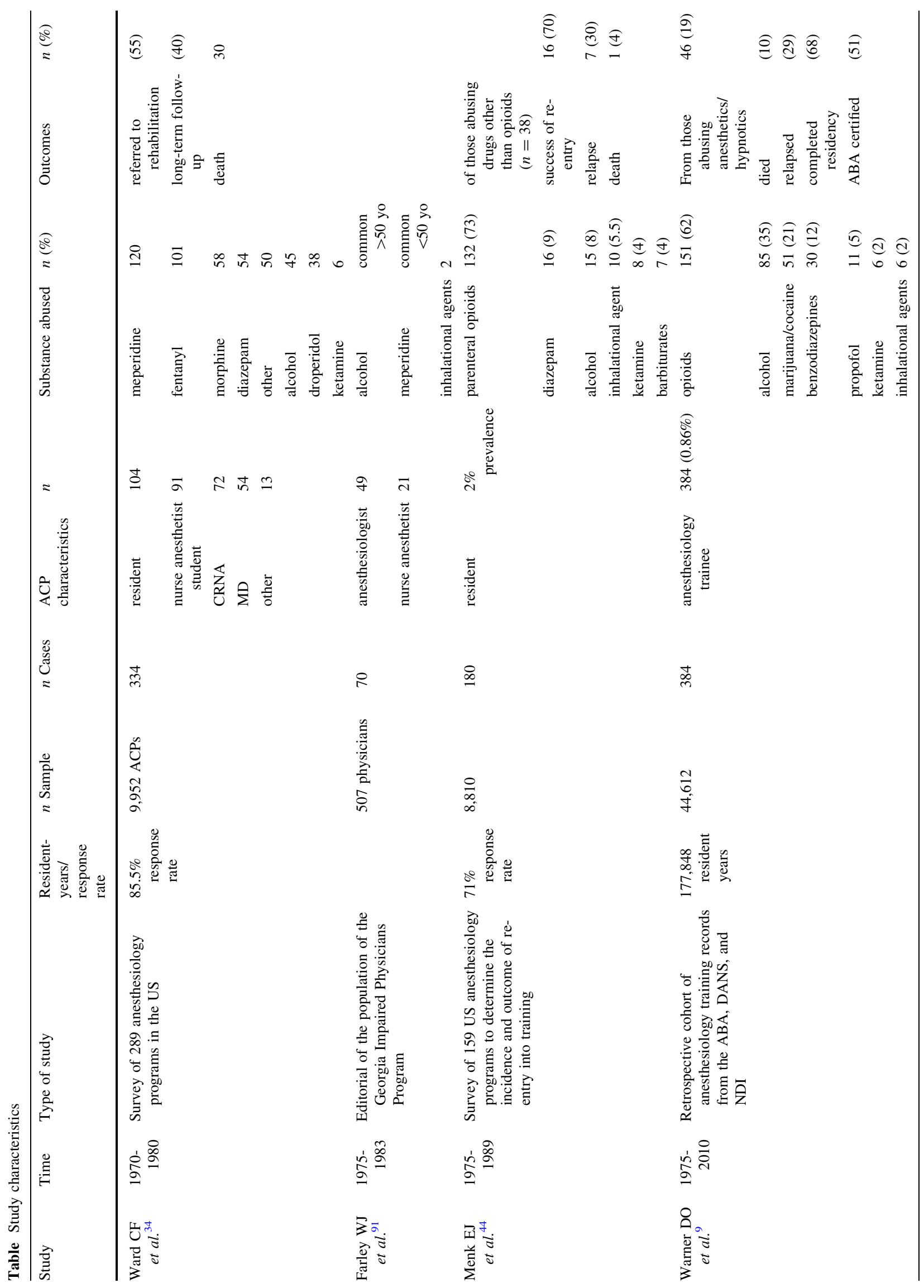




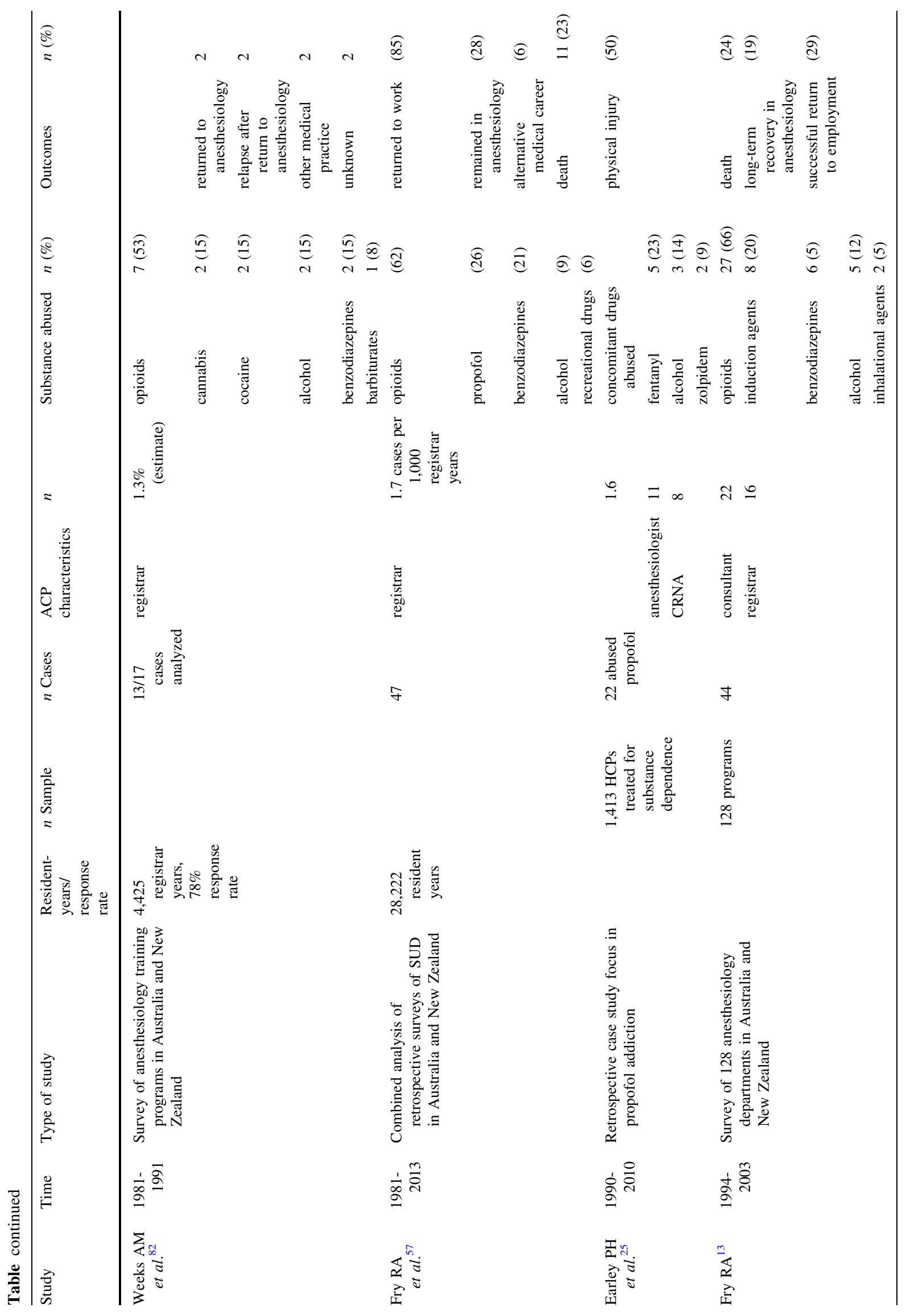




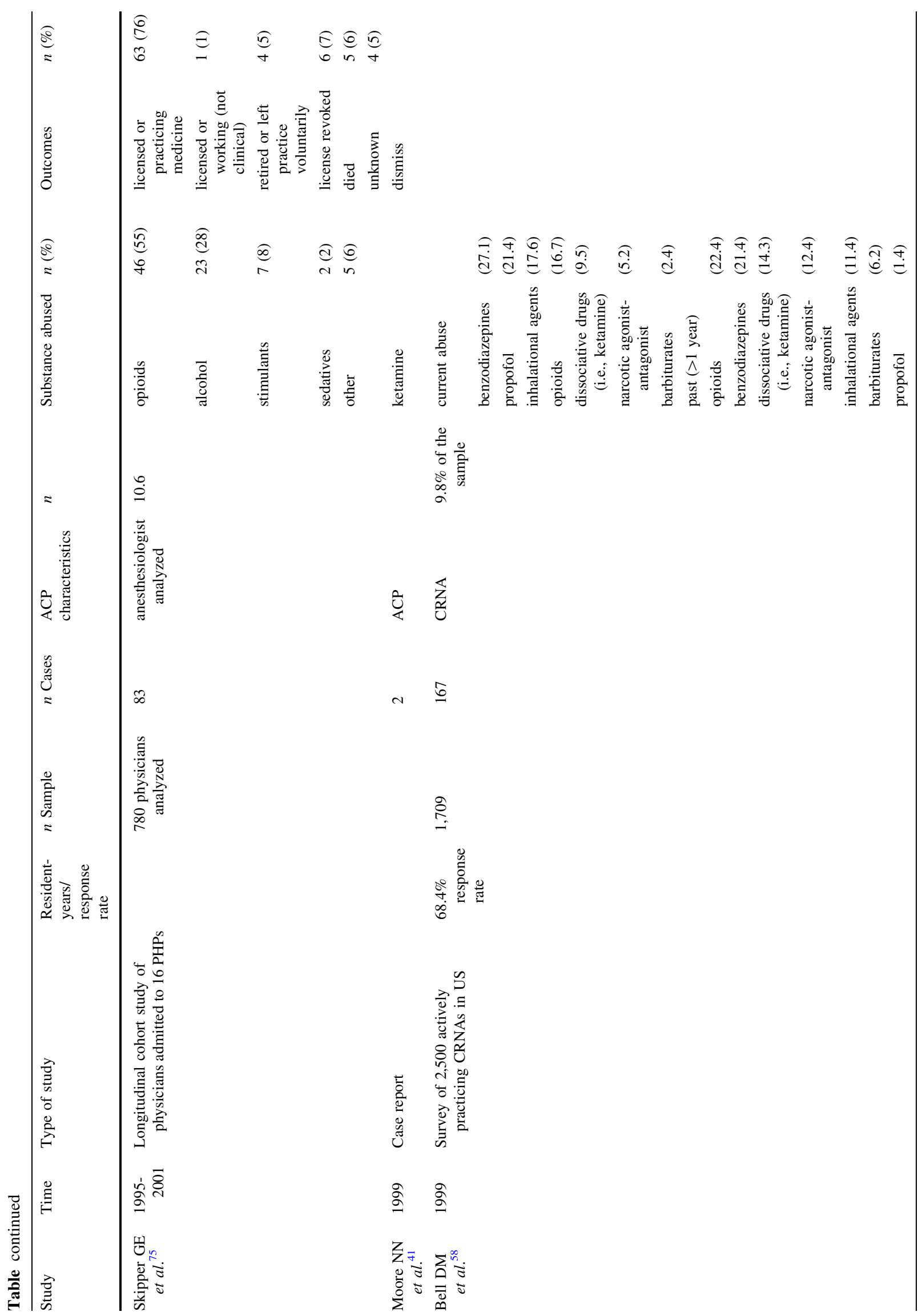




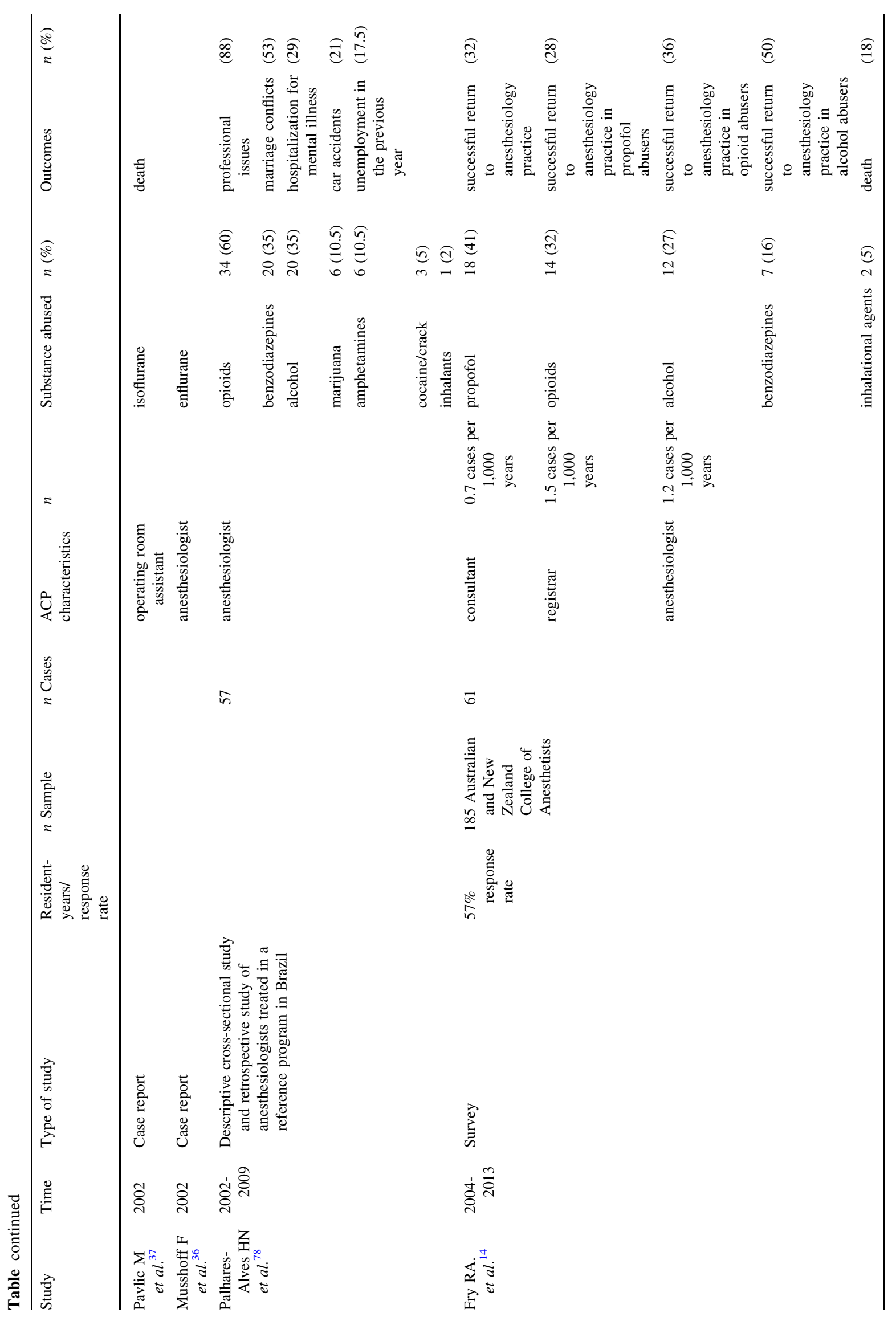




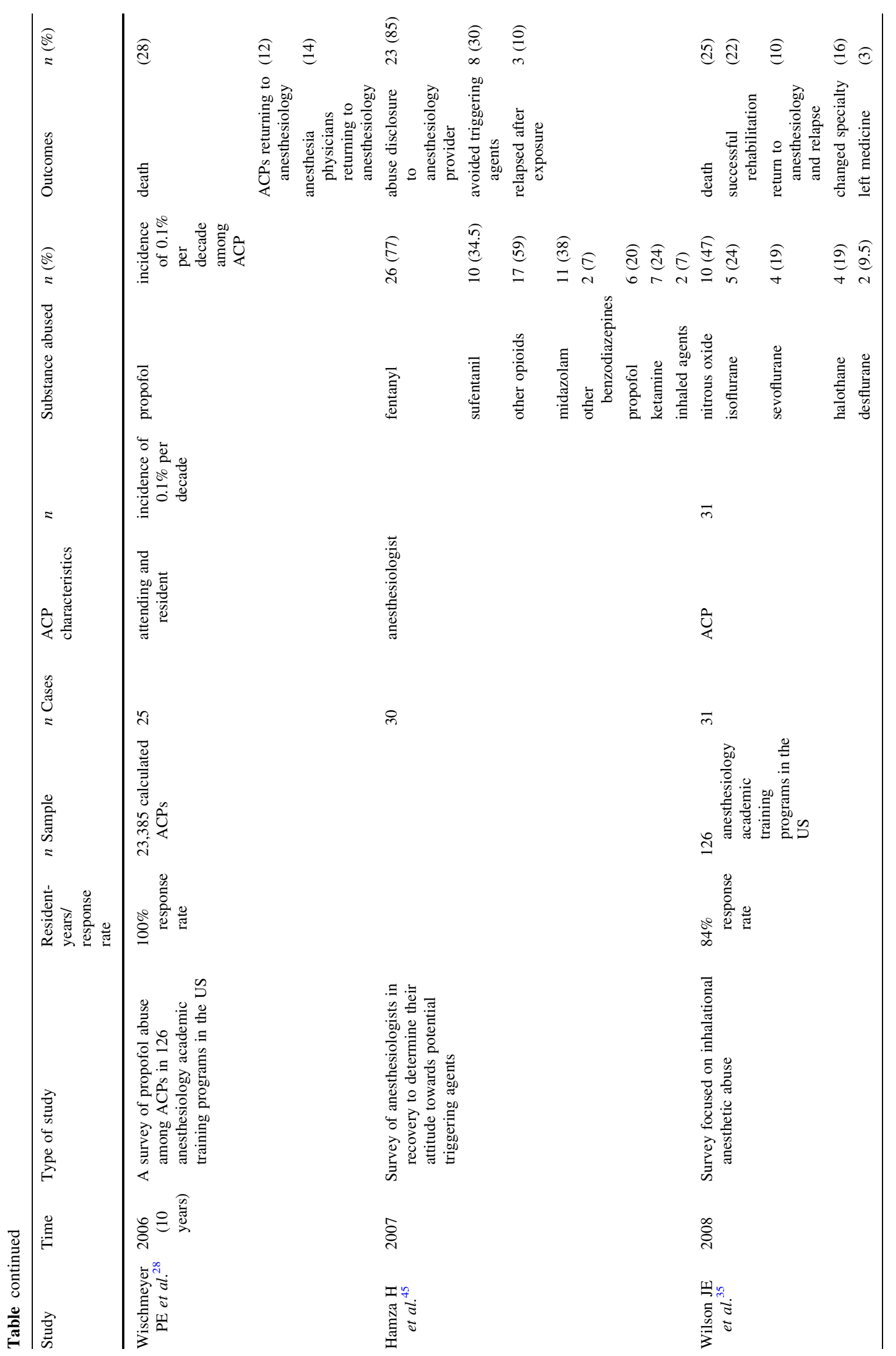




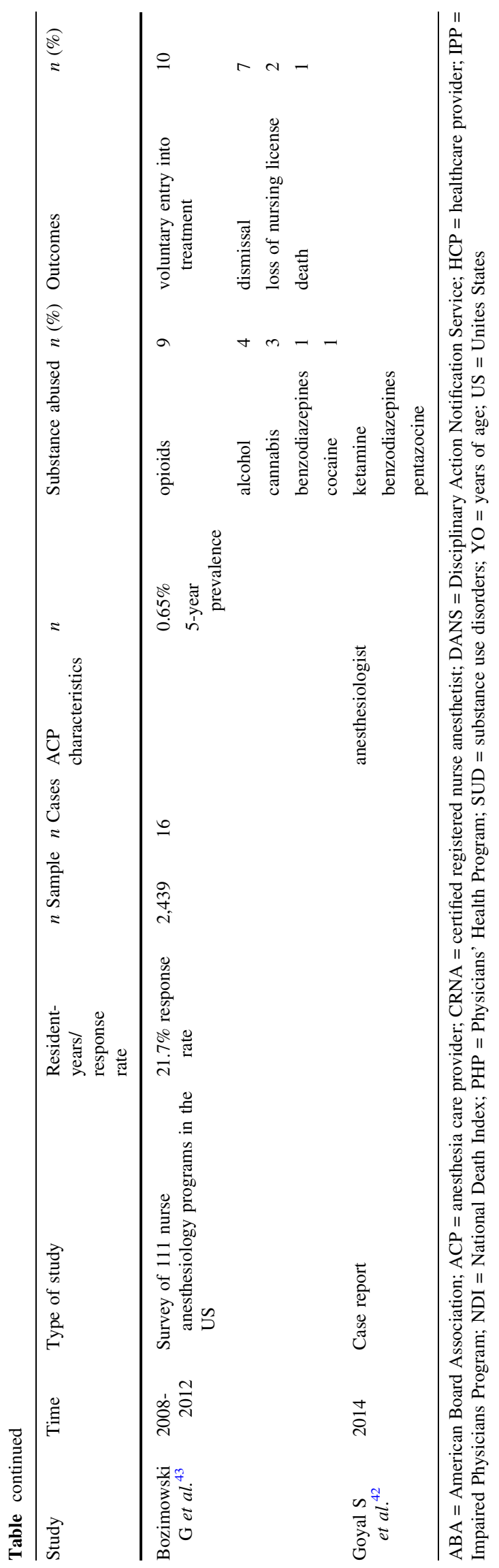

Addiction is defined as a chronic condition characterized by compulsive and relentless behaviour entailing negative consequences. ${ }^{15}$ It manifests as a cognitive, physiologic, and behavioural complex of symptoms related to the maladaptive pattern of substance abuse. ${ }^{3,15}$ Potential predisposing factors that are specific to ACPs include high levels of work-related stress and ease of access to controlled substances. ${ }^{8,13,16,17}$ In addition, some have postulated that the chronic exposure to low levels of anesthetic gas contaminants could also be a predisposing factor. ${ }^{16,18,19}$

It has been proposed that addiction-associated craving and compulsive drug-seeking and drug-taking behaviour result from reward system dysregulation, reward mechanism hypersensitization, and cognitive difficulties in decision-making and judgement capacity. ${ }^{15}$

Advances in the neurobiology of drug addiction have enabled the identification of underlying biological mechanisms that are initiated after exposure to addictive substances. The mesolimbic system is involved in euphoria, acute reinforcement, and withdrawal syndrome. Addictive drugs act via modification of mesocorticolimbic dopaminergic input into the nucleus accumbens and prefrontal cortex. ${ }^{20}$ This process occurs under strict epigenetic regulation of local histone deacetylases and other modifiers of gene expression. ${ }^{21}$ Operating in parallel, the mesocortical system is implicated in drug experience, craving, and compulsion. Unlike natural reward processes, habituation is not present in addictive drug responses; rather, the administration of each dose activates dopamine release, which promotes drug-rewarding effects. These drug-rewarding properties are implicated in behavioural sensitization and environmental cues, which ultimately contribute to the relapse. $^{15}$

Both individual-specific factors and addictive properties of the drug itself mediate development of drug abuse and dependence. Genetic factors, personality type, and concomitant psychiatric disorders may predispose an individual to the problem. An increased propensity to drug abuse has been described in patients diagnosed with schizophrenia, depression, anxiety, bipolar disorder, as well as attention deficit and hyperactivity disorder (ADHD). ${ }^{15}$ The decision to abuse an addictive substance may be influenced by personality traits. Interestingly, individuals with similar personalities commonly abuse similar drugs. For example, individuals diagnosed with ADHD often abuse amphetamines, whereas individuals suffering from anxiety and depression tend to abuse opioid medications. ${ }^{22}$

\section{Drugs implicated in abuse}

In addition to the genetic, biochemical, and psychological variability of individuals, another important determinant in the development of drug abuse is the drug's pharmacokinetic and pharmacodynamic profile. ${ }^{15}$ Drugs reaching high brain 


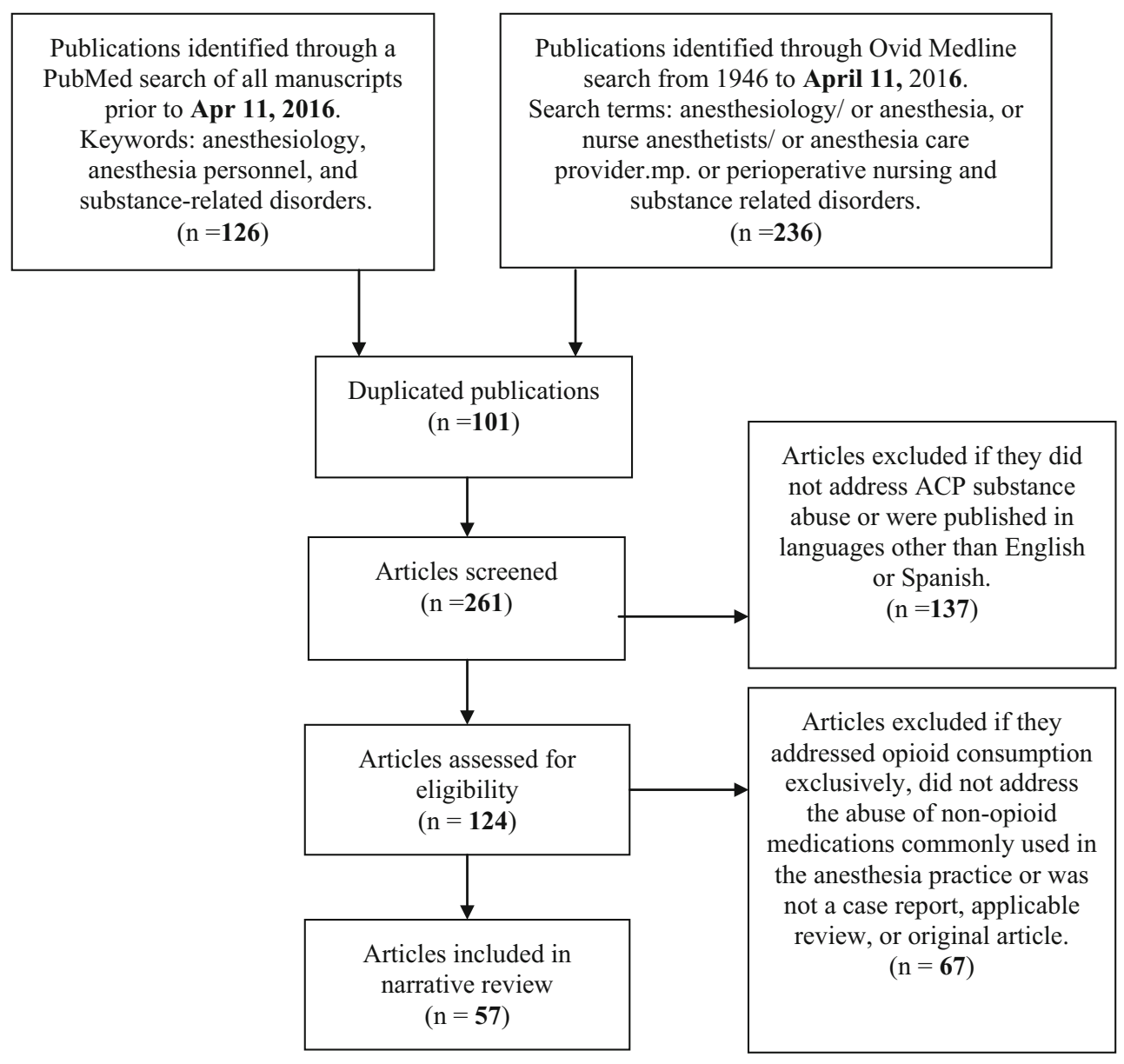

Figure Non-opioid anesthetic abuse among anesthesia care providers; flow diagram of article selection. $\mathrm{ACP}=$ anesthesia care providers; $\mathrm{MP}=$ multipurpose

concentrations within a short time after administration have a high attractiveness quotient and are more favoured by drug abusers. ${ }^{15}$ Drug delivery systems that allow for rapid onset and intensity also influence abuse (e.g., water solubility, volatility, and heat resistance facilitates intravenous administration, inhalation, and smoking, respectively). Furthermore, the alteration of the drug delivery system by injection, snorting, and chewing is a common practice. ${ }^{23,24}$

Many of the medications utilized in everyday anesthesia practice are administered by the intravenous or inhaled routes, and they have a high addictive potential given that they reach high brain concentrations very quickly upon administration. We review the non-opioid anesthetic medications most commonly abused by ACPs: propofol, inhalational agents, ketamine, and benzodiazepines. ${ }^{1,9,13}$

\section{Propofol}

Propofol (2,6-diisopropylphenol) was introduced into clinical practice in the late 1980s. Propofol's pharmacokinetic and biochemical properties have made it the intravenous induction agent of choice in more than 50 countries in the world. ${ }^{25}$

In parallel to the widespread application of propofol as an induction agent, several studies have described its misuse and abuse among ACPs. ${ }^{25}$ Elation, euphoria, sexual disinhibition, and pleasurable feelings are frequently reported by patients and individuals misusing propofol, which may contribute to its potential for abuse. ${ }^{25-27}$ Propofol has recently been reported to be the most commonly abused anesthesia medication among ACPs in Australia and New Zealand, accounting for $41 \%$ of cases from 2004-2013. ${ }^{14}$ In the United States, Wischmeyer et al. (2007) reported a fivefold increase in propofol abuse after comparing two time periods during 1990-2005. The authors found a $0.10 \%$ incidence in propofol abuse among 20,865 attendings and residents during 1995-2005. This was in contrast to a calculated ten-year incidence of $0.02 \%$ based on findings by Booth et al. among 11,666 attendings and residents during 1990-1997. ${ }^{1,28}$ 
The initial warning on propofol abuse appeared in 1992 when Follette and Farley reported the first case of its misuse. ${ }^{29}$ The ability of propofol to act on the reward mechanisms in the brain as well as its widespread use and availability contribute to the potential for abuse. ${ }^{30}$ In vivo studies after propofol administration have shown characteristics similar to other drugs of abuse, in particular, an increase in ventral tegmental dopaminergic excitability and elevated dopamine levels in the nucleus accumbens. ${ }^{25,30}$

High lipid solubility and rapid accumulation in the brain account for the fast onset of anesthesia after propofol injection. Its subsequent redistribution permits fast clinical recovery, thereby facilitating the "hiding behaviour" among drug abusers. ${ }^{8}$ The lack of accounting by operating room pharmacies generally facilitates incidents of propofol self-injection. ${ }^{28}$ Fewer cases of propofol abuse have been reported in anesthesia departments where propofol distribution was under enhanced pharmacy regulation. ${ }^{28,31}$

A recently published study of 22 treatment cases for propofol addiction indicated that $82 \%$ met the criteria for drug dependence in keeping with the Diagnostic and Statistical Manual of Mental Disorders, Fourth Edition. Signs of tolerance and withdrawal were present in $50 \%$ and $18 \%$ of users, respectively. ${ }^{25}$ Propofol tolerance leads to escalations in drug dosages and more frequent consumption. In addition, withdrawal contributes significantly to the abusive potential of the drug by producing dysphoria and physical symptomatology, which prompts further use. ${ }^{15}$

Craving has been identified as the dominant symptom of propofol withdrawal. Other withdrawal symptoms described include somnolence and difficulties in concentration, anxiety, stress, and hyperhydrosis. ${ }^{27,30,32}$ The currently available information is insufficient for proper characterization of propofol withdrawal syndrome $^{30}$ Both tolerance and withdrawal reflect adaptation of the body to the drug effects and contribute to risk-taking and drug-seeking behaviour. ${ }^{15}$

Lethal cases of propofol abuse among healthcare providers are not infrequent, particularly among ACPs and anesthesiology residents, with mortality rates reaching $28 \%$ and up to $38 \%$, respectively. ${ }^{28}$ Since propofol blunts airway protective reflexes and respiratory drive, uncontrolled and rapid self-administration may lead to respiratory depression, anoxic brain injury, aspiration pneumonitis, and cardiac arrest. ${ }^{25}$ In addition, propofol infusion syndrome, development of hypoxia, and cardiorespiratory arrest have been described as causes of sudden death in chronic propofol abusers. ${ }^{26}$ To avoid these complications of addiction, hospitals and departments have established preventive strategies to reduce diversion of this drug. ${ }^{33}$ Preemptive measures, including routine drug screening, pharmacy accounting, and restricting access to propofol, may help to identify and properly manage abusive behaviour among ACPs and prevent compromise to patient care.

\section{Inhalational agents}

A 1983 report cited no cases of inhalational anesthetic use for recreational purposes among anesthesiology residents. ${ }^{34}$ More recently, inhalational agents have been reported to account for $5 \%$ of substances abused by ACPs in Australia and New Zealand ${ }^{14}$ and $2 \%$ of substances abused by anesthesiology residents in the United States. ${ }^{9,14}$ Wilson et al. (2008) surveyed 106 anesthesiology residency programs in the United States to determine the prevalence of inhalational anesthetic abuse. Twenty-two percent of programs reported at least one case of abuse or other misappropriation of an inhalational anesthetic. Of 31 identified cases, $47 \%$ involved the abuse of nitrous oxide $\left(\mathrm{N}_{2} \mathrm{O}\right), 24 \%$ isoflurane, $19 \%$ sevoflurane, $19 \%$ halothane, and $9.5 \%$ desflurane. ${ }^{35}$ In this report, trainees accounted for the greatest number of cases of inhalational agent abuse (14/31), followed by nurse anesthetists $(6 / 31)$, consultants $(5 / 31)$, and anesthesia technicians $(2 / 31) .{ }^{35}$ The mortality rate among the 31 cases of volatile agent abuse in this study was $26 \%$, including five trainees and two consultants. ${ }^{35}$ Fifty-five percent of reported cases of inhalational agent abuse occurred after 2000, suggesting an increasing prevalence or improved reporting/surveillance. ${ }^{35-37}$

A proposed mechanism of volatile anesthetic and $\mathrm{N}_{2} \mathrm{O}$ action on neural networks and signal conduction involves an enhanced facilitation of inhibitory signalling $(\gamma-$

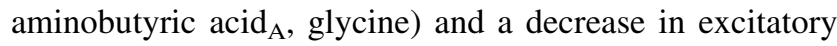
neurotransmission (nicotinic acetylcholine, N-methyl-Daspartate [NMDA], $\alpha$-amino-3-hydroxy-5-methyl-4isoxazolepropionic acid, and opioid receptors). Similar mechanisms are thought to be involved in the establishment of abusive potential of inhalational anesthetics. ${ }^{38-40}$ Euphoria and psychedelic-like effects of $\mathrm{N}_{2} \mathrm{O}$ and other inhalational anesthetics are explained by their NMDA antagonizing properties. ${ }^{39}$ Nevertheless, the exact neural mechanisms mediating their abusive potential are yet to be determined. Dependence and abuse of inhalational anesthetics seriously impacts the personal health and professional conduct of ACPs. Among anesthesia providers who abuse inhalational agents, only $22 \%$ (7/31) were reported to be capable of returning to practice. $^{14,35}$ Appropriate measures to ensure enhanced accountability and more effective pharmacy regulation of inhalational agents could help reduce the incidence of their abuse by ACPs. ${ }^{14}$ Wilson et al. reported that only $7 \%$ of 
anesthesia departments rely on pharmacy regulations of inhalational anesthetics. ${ }^{35}$ As in the case of propofol, ease of access, inadequate pharmacy accounting, difficulties in detection and lack of screening procedures play a role in the development of abusive behaviour among ACPs and make their rehabilitation even more problematic.

\section{Ketamine}

Ketamine, a structural analogue of phencyclidine and a central nervous system NMDA receptor antagonist, was first introduced into clinical practice as an intravenous anesthetic in $1970 .^{41}$ It has gained popularity as a safe and cost-effective drug for the induction of anesthesia, pain control for dressing changes, bronchoscopy, and general pain control in all age groups. ${ }^{1,41-43}$ By 1990, ketamine represented about $4 \%$ of drugs abused by anesthesiology residents. ${ }^{44}$ A more recent report cited ketamine as the initial substance abused in $2 \%$ of anesthesiology resident cases. ${ }^{9}$ When evaluating ACPs in addiction recovery programs, Hamza et al. found that seven of 27 respondents with a history of substance abuse reported ketamine consumption. ${ }^{45}$ Interestingly, ketamine abuse varies largely amongst studies.

Though the dissociative properties of ketamine make it useful for the induction and maintenance of anesthesia, its potential for abuse by ACPs might be related to its hallucinogenic and calming effects, as described by Moore and Bostwick. ${ }^{41}$ These neuropsychological and other effects, such as delusions, delirium, confusion, and depersonalization, ${ }^{46-49}$ could be related to the inhibition of norepinephrine, dopamine, and serotonin uptake as well as the inhibition of cholinergic neuron activation of the prefrontal cortex. ${ }^{46}$

Compared with other anesthetics, ketamine abuse is associated with less risk of immediate life-threatening effects due to its wide therapeutic range and the stability of cardiorespiratory function during ketamine anesthesia. ${ }^{50}$ Nonetheless, it causes sympathetic hyperactivity in drug abusers and induces gastrointestinal and urological complaints. While the mortality of ACPs who abuse ketamine has not been well studied, severe or fatal intoxication of ketamine has been described in non-ACPs who were co-intoxicated with ethanol, opiates, amphetamines, or cocaine. ${ }^{51}$ Chronic effects of ketamine abuse include ulcerative cystitis, muscle cramps, cognitive impairment, as well as a decrement in spatial working memory, pattern recognition, and verbal recognition memory. ${ }^{50,52}$ Additional long-term complications of ketamine abuse include memory impairment, attention dysfunction, tolerance, and flashbacks. ${ }^{41}$ Cognitive dysfunction and related symptoms are explained by central NMDA receptor antagonism. ${ }^{52}$
Magnetic resonance imaging studies have revealed multifocal degeneration and atrophic areas within the brain tissue of individuals with a history of ketamine abuse. ${ }^{51,53}$ These morphological changes correlate with the development of cognitive and behavioural dysfunction. ${ }^{54}$

\section{Benzodiazepines}

Benzodiazepines (BZDs) have been widely prescribed for more than 50 years for treatment of anxiety and insomnia. Their potential for dependence and addiction was first described by Hollister et al. in $1961 .^{55}$ In many cases of BZD abuse, including those involving ACPs, the drug is initially prescribed by healthcare providers for relief from stress and insomnia. Nevertheless, this drug group has significant potential for dependence, and many chronic BZD users transition into misuse and end up taking the medication outside the recommended dose and/or beyond the recommended time frame (so-called "involuntary" or iatrogenic dependence). ${ }^{55}$

For some, the psychoactive properties of BZDs have been described as desirable and contribute to the drug's potential for intentional abuse. It is commonly associated with a concomitant history of substance misuse and a comorbid diagnosis of another substance misuse disorder. ${ }^{55}$

For anesthesiologists, BZDs are among the most commonly abused controlled substances. ${ }^{34,56}$ Fry et al. recently reported that $16 \%$ of substance abuse cases among ACPs involved BZDs, ${ }^{13,14}$ while Warner et al. cited BZD abuse in $12 \%$ of substance abuse cases among anesthesiology residents. ${ }^{9,57}$ Bell et al. found that midazolam is the most commonly misused drug among certified registered nurse anesthetists, with intranasal administration being the preferred route of administration. ${ }^{58,59}$

Benzodiazepine consumption causes dose-dependent motor and cognitive effects, the extent of which depends on the specific properties of the drug and individual sensitivity. Consumption of BZDs can impair attentiveness and affect performance of simple repetitive and complex tasks as well as higher brain functions such as learning and memory (mainly anterograde memory). ${ }^{55}$ The severity of symptoms is more pronounced with prolonged drug consumption and may be especially debilitating in chronic users.

Preventive measures and therapeutic approaches

Vigorous efforts have been taken to prevent, detect, and treat cases of ACPs involved in substance abuse activities. Currently, the Accreditation Council for Graduate Medical Education and the American Society of Anesthesiologists recommend that anesthesiology departments have a formal 
substance abuse policy and an education course for trainees and personnel. ${ }^{60}$ Nevertheless, in spite of efforts towards better education and information regarding the risks and hazards related to substance abuse, its incidence among ACPs is not decreasing. ${ }^{61}$ Given the increasing role of hypnotic and general anesthetic agents as drugs of abuse among ACPs, it is important to educate trainees and ACPs to recognize more clearly the risks associated with nonopioid drug abuse in anesthesia practice. ${ }^{62}$ Preventive strategies can be instituted to facilitate active detection of diversion, for example, proper regulation of controlled drugs and substances with the potential for abuse. ${ }^{33,63-68}$ Other important preventive measures include random drug screening ${ }^{69-73}$ and performance assessment conducted by properly trained personnel to detect the problem in its early stages. ${ }^{9,60,74}$

Once substance abuse has been identified, ACPs can be referred to programs that specialize in physicians with substance use disorders. Current programs in the United States, such as state physicians' health programs (PHP) described by DuPont et al., ${ }^{12}$ provide initial residential or close outpatient treatment and continuous outpatient monitoring. During the first year of treatment, patients commonly receive regular counselling, clinical supervision, and substance use monitoring. These programs provide intensive therapy with total abstinence and intense regular follow-up that includes weekly meetings, 12-step program participation, work site monitoring, and random urine testing. The frequency of patient monitoring decreases over time but is intensified with relapse episodes. In addition, these programs work closely with the state medical licensing boards, and monitoring commonly extends for five or more years. ${ }^{12,75}$ Although these approaches are not designed specifically for the treatment of substances like propofol, volatile agents, ketamine, and benzodiazepines, they have generally been shown to provide successful treatment of substance abuse disorders for extended periods of time. ${ }^{12,76}$ The requirement for a specific approach and the success of current programs in treating abuse of non-opioid anesthetic medications have not been adequately studied.

When compared with other physicians, the outcomes for anesthesiologists are similar with respect to survival, total abstinence, completion of monitoring, return to work in their profession, and retention of their medical license. ${ }^{75} \mathrm{In}$ order to achieve long-term recovery and a successful return to practice, active patient participation is required along with continuous monitoring and supervision at the local level and by the medical licensing boards. Such an approach will increase the chances of effective recovery and successful return to practice. According to data from 16 PHPs in the United States, 75-90\% of the involved physicians and $71 \%$ of anesthesiologists successfully complete their treatment, ${ }^{12}$ which typically includes a five-year course of care and requires specialized posttreatment monitoring over a time period specified by the organization. ${ }^{12,76}$

In the United States, the Americans with Disabilities Act mandates that treated abusers have an opportunity to return to work. ${ }^{77}$ Nonetheless, the aforementioned work by Domino et al. showed that, during 1991-2001, 25\% of 2,922 anesthesiologists who were part of the Washington PHP relapsed at least once. ${ }^{2}$ The use of opioids played a major role in these relapses. In this report, we discuss nonopioid drug abuse in which such conclusions are less clear. Further work is needed in order to draw accurate associations and conclusions about the relapse rate of ACPs in regard to non-opioid substance abuse and their ability to accomplish a successful return to clinical practice.

\section{Impact}

Substance abuse is a chronic condition that substantially impacts the lives and careers of anesthesiologists in training ${ }^{78}$ and potentially threatens patient safety. The strong desire and compulsions associated with substance abuse often lead the practitioner to neglect personal interests and duties, including residency training and patient care. This can eventually lead to decreased work performance, potential patient harm, and subsequent provider and hospital liability. ${ }^{13}$ While there are concerns about recovering ACPs returning to practice, a review of a large database did not reveal any patient injuries inflicted by previously addicted ACPs. ${ }^{79}$ Nevertheless, the authors point out that substance abuse can be concealed, and this would make the role of substance abuse in anesthesia patient safety a difficult issue to assess. Conversely, Berry et al. conducted a survey of 104 anesthesiology programs in the United Kingdom and Ireland which showed that absenteeism or poor work performance, excessive writing of patient prescriptions, and use of drugs at work were the most common signs for recognition of abuse ${ }^{80}$ One study did report that incompetence and patient accidents were signs for recognition of abuse in $27 \%$ and $10 \%$ of cases, respectively. ${ }^{13}$ State PHP programs report a $6 \%$ relapse during medical practice and one event of patient harm (overprescription) among 904 patients admitted to the programs during 1995-2001. Nevertheless, they do not specify the number of anesthesia providers who relapsed or the specific drug they abused. ${ }^{12}$

Personal well-being, autonomy, and financial stability are jeopardized by substance abuse. ${ }^{78,81}$ Sadly, lethal overdose or suicide is the presenting sign of abuse in up to $15 \%$ of reported cases, and the rate of accidental lethal 
overdose is even higher among residents, reaching $23 \%{ }^{9,13,82,83}$ There is also an increased risk of death from drug-related suicide (relative risk [RR], 2.21; 95\% confidence interval [CI], 1.33 to 3.66) and drug-related deaths (RR, 2.79; 95\% CI, 1.87 to 4.15) in anesthesiologists when compared with general internists. ${ }^{84}$ Interpersonal relationship problems, frequent illness, reclusive behaviour, depression, or agitation are the most common features seen at the time of diagnosis. ${ }^{82} \mathrm{An}$ inappropriate approach to confronting an addicted ACP can lead to desperation and suicide. Once the addiction is identified and an intervention is planned, it is important to adhere faithfully to institutional policies and state laws in order to prevent catastrophic effects. ${ }^{85}$ Considering that financial difficulties are one of the reported causes of abuse, it is important to consider the impact of abuse on an ACP's financial stability as a recovery stressor. Unfortunately, substance misuse can lead to an increased risk of adverse training outcomes, such as failure to complete residency (odds ratio, 14.9; 95\% CI, 9.0 to 24.6), ${ }^{86}$ or for anesthesiologists, unsuccessful return to anesthesia practice in up to $72 \%$ of propofol abusers and $68 \%$ of substance abusers. ${ }^{14}$

The results of currently practiced approaches to addiction treatment are encouraging. The rates of successful completion of anesthesia residency by residents with chemical dependence have increased from $46 \%$ as per Collins et al. in $2005^{87}$ to $60 \%$ according to Bryson and Levine in $2008^{88}$ and to $69 \%$ according to Warner et al. in 2013. ${ }^{9}$ The attitude of anesthesiology departments towards allowing recovering residents to return to anesthesiology training differs among institutions. ${ }^{89}$ Programs may be hesitant to take on the responsibility of monitoring the safety and well-being of a recovering trainee. Concern for constant exposure to controlled substances and the lethal consequences of relapse may also prompt programs to discourage a return to the field of anesthesiology. ${ }^{75}$ On the other hand, some programs have made efforts that support rehabilitation and successful return of trainees to anesthesiology practice. Some have developed novel strategies to support the recovery of anesthesiology residents. ${ }^{88}$ Such efforts include early participation of recovering residents in anesthesiology research and education while working in the anesthesia simulation centre. Such an approach provides residents in early addiction recovery with a flexible schedule and the financial means to continue treatment for at least a year before returning to anesthesia practice. ${ }^{86,88}$

Substance abuse has substantial detrimental effects on healthcare workers' lives and careers. ${ }^{78,90}$ Warner et al. recently published a sobering example. The authors found that the likelihood of death among anesthesiology residents with substance abuse disorders was $14.1 \%$ over a median follow-up time of 14 years, while the rate of death among a control group was only $1.3 \%$ over 15 years of median follow-up time. Most of these deaths occurred within a tenyear period after the completion of training. ${ }^{86}$

\section{Conclusion}

Drug abuse among anesthesia providers has become a serious matter of concern requiring better understanding, further research, and a multidisciplinary approach to treatment. Besides the well-studied problem of opioid abuse among ACPs, there is increasing evidence regarding the impact of non-opioid anesthetic drug abuse. Specifically, propofol, benzodiazepines, inhalational anesthetics, and ketamine have been implicated in abusive behaviour among ACPs and other healthcare professionals with access to these medications. The incidence of such reports is increasing, and regulatory and therapeutic measures are required for effective identification, treatment, and monitoring of individuals involved in anesthetic drug abuse. Substance abuse has the potential to jeopardize patient care and adversely affects both personal lives and professional careers. While reintegration of trainees and anesthesiologists with substance abuse disorders into clinical practice is a complicated and potentially controversial topic, it is an issue that many programs and practices will be forced to navigate. Awareness of the potential for abuse of both opioid and non-opioid drugs is essential. Focused educational programs, proper screening and identification of individuals involved in drug abuse are essential prerequisites for safe and effective medical training in fields that handle controlled substances. Long-term treatment and extended monitoring in physicians' health programs will help reduce morbidity and mortality and increase the number of healthcare providers capable of a safe return to medical practice.

Funding None.

Conflicts of interest None declared.

Author contributions Alix Zuleta-Alarcón wrote and revised the manuscript and was responsible for the literature search. John C. Coffman, Thomas J. Papadimos, and Sergio D. Bergese shared their academic expertise. John C. Coffman, Suren Soghomonyan, Thomas J. Papadimos, and Sergio D. Bergese critically reviewed the manuscript. Kenneth $R$. Moran was the principal investigator responsible for the concept of this review, and he participated in writing the manuscript. Kenneth R. Moran and Alix Zuleta-Alarcón were responsible for coordination of the review and communication with all co-authors.

Editorial responsibility This submission was handled by Dr. Hilary P. Grocott, Editor-in-Chief, Canadian Journal of Anesthesia. 


\section{References}

1. Booth JV, Grossman D, Moore J, et al. Substance abuse among physicians: a survey of academic anesthesiology programs. Anesth Analg 2002; 95: 1024-30.

2. Domino $K B$, Hornbein $T F$, Polissar $N L$, et al. Risk factors for relapse in health care professionals with substance use disorders. JAMA 2005; 293: 1453-60.

3. Baldisseri MR. Impaired healthcare professional. Crit Care Med 2007; 35: S106-16.

4. Hughes PH, Conard SE, Baldwin DC Jr, Storr CL, Sheehan DV. Resident physician substance use in the United States. JAMA 1991; 265: 2069-73.

5. Oreskovich MR, Shanafelt T, Dyrbye LN, et al. The prevalence of substance use disorders in American physicians. Am J Addict 2014. DOI:10.1111/j.1521-0391.2014.12173.x.

6. Lutsky I, Hopwood M, Abram SE, Jacobson GR, Haddox JD, Kampine JP. Psychoactive substance use among American anesthesiologists: a 30-year retrospective study. Can J Anaesth 1993; 40: 915-21.

7. Merlo LJ, Singhakant S, Cummings SM, Cottler LB. Reasons for misuse of prescription medication among physicians undergoing monitoring by a physician health program. J Addict Med 2013; 7 : 349-53.

8. Bryson EO, Hamza $H$. The drug seeking anesthesia care provider. Int Anesthesiol Clin 2011; 49: 157-71.

9. Warner DO, Berge K, Sun H, Harman A, Hanson A, Schroeder $D R$. Substance use disorder among anesthesiology residents, 1975-2009. JAMA 2013; 310: 2289-96.

10. Talbott GD, Gallegos KV, Wilson PO, Porter TL, The Medical Association of Georgia's Impaired Physicians Program. Review of the first 1000 physicians: analysis of specialty. JAMA 1987; 257: 2927-30.

11. Gallegos $K V$, Browne $C H$, Veit FW, Talbott GD. Addiction in anesthesiologists: drug access and patterns of substance abuse. QRB Qual Rev Bull 1988; 14: 116-22.

12. DuPont RL, McLellan AT, White WL, Merlo LJ, Gold MS. Setting the standard for recovery: Physicians' Health Programs. J Subst Abuse Treat 2009; 36: 159-71.

13. Fry RA. Substance abuse by anaesthetists in Australia and New Zealand. Anaesth Intensive Care 2005; 33: 248-55.

14. Fry RA, Fry LE, Castanelli DJ. A retrospective survey of substance abuse in anaesthetists in Australia and New Zealand from 2004 to 2013. Anaesth Intensive Care 2015; 43: 111-7.

15. Cami J, Farre M. Drug addiction. N Engl J Med 2003; 349: 97586.

16. Merlo LJ, Goldberger BA, Kolodner D, Fitzgerald K, Gold MS. Fentanyl and propofol exposure in the operating room: sensitization hypotheses and further data. J Addict Dis 2008; 27: $67-76$

17. McDonnell NJ, Kaye RM, Hood S, Shrivastava P, Khursandi DC. Mental health and welfare in Australian anaesthetists. Anaesth Intensive Care 2013; 41: 641-7.

18. McAuliffe PF, Gold MS, Bajpai L, et al. Second-hand exposure to aerosolized intravenous anesthetics propofol and fentanyl may cause sensitization and subsequent opiate addiction among anesthesiologists and surgeons. Med Hypotheses 2006; 66: 874-82.

19. Gold MS, Melker RJ, Dennis DM, et al. Fentanyl abuse and dependence: further evidence for second hand exposure hypothesis. J Addict Dis 2006; 25: 15-21.

20. Renthal W, Nestler EJ. Histone acetylation in drug addiction. Semin Cell Dev Biol 2009; 20: 387-94.

21. Yeh HH, Tian M, Hinz R, et al. Imaging epigenetic regulation by histone deacetylases in the brain using PET/MRI with (1)(8)FFAHA. Neuroimage 2013; 64: 630-9.
22. Garcia-Guasch $R$, Roige $J$, Padros $J$. Substance abuse in anaesthetists. Curr Opin Anaesthesiol 2012; 25: 204-9.

23. Passik SD, Hays L, Eisner N, Kirsh KL. Psychiatric and pain characteristics of prescription drug abusers entering drug rehabilitation. J Pain Palliat Care Pharmacother 2006; 20: 5-13.

24. Schaeffer T. Abuse-deterrent formulations, an evolving technology against the abuse and misuse of opioid analgesics. J Med Toxicol 2012; 8: 400-7.

25. Earley PH, Finver T. Addiction to propofol: a study of 22 treatment cases. J Addict Med 2013; 7: 169-76.

26. Bryson EO, Frost EA. Propofol abuse. Int Anesthesiol Clin 2011; 49: 173-80.

27. Bonnet $U$, Scherbaum N. Craving dominates propofol addiction of an affected physician. J Psychoactive Drugs 2012; 44: 186-90.

28. Wischmeyer PE, Johnson BR, Wilson JE, et al. A survey of propofol abuse in academic anesthesia programs. Anesth Analg 2007; 105: 1066-71.

29. Follette JW, Farley WJ. Anesthesiologist addicted to propofol. Anesthesiology 1992; 77: 817-8.

30. Wilson C, Canning P, Caravati EM. The abuse potential of propofol. Clin Toxicol (Phila) 2010; 48: 165-70.

31. Shrivastava PP, Zuccherelli L. Can we all survive propofol? Anaesth Intensive Care 2015; 43: 9-11.

32. Bonnet U, Harkener J, Scherbaum N. A case report of propofol dependence in a physician. J Psychoactive Drugs 2008; 40: 215-7.

33. Weetman DB, Mascardo LA, Ross MB, Abramowitz PW. Propofol as a drug of diversion. Am J Health Syst Pharm 2004; 61: 1185-6.

34. Ward CF, Ward GC, Saidman LJ. Drug abuse in anesthesia training programs. A survey: 1970 through 1980. JAMA 1983; 250: $922-5$

35. Wilson JE, Kiselanova $N$, Stevens $Q$, et al. A survey of inhalational anaesthetic abuse in anaesthesia training programmes. Anaesthesia 2008; 63: 616-20.

36. Musshoff $F$, Junker H, Madea B. An unusual case of driving under the influence of enflurane. Forensic Sci Int 2002; 128: 1879.

37. Pavlic M, Haidekker A, Grubwieser P, Rabl W. Fatal accident caused by isoflurane abuse. Int J Legal Med 2002; 116: 357-60.

38. Campagna JA, Miller KW, Forman SA. Mechanisms of actions of inhaled anesthetics. N Engl J Med 2003; 348: 2110-24.

39. Beckman NJ, Zacny JP, Walker DJ. Within-subject comparison of the subjective and psychomotor effects of a gaseous anesthetic and two volatile anesthetics in healthy volunteers. Drug Alcohol Depend 2006; 81: 89-95.

40. Yamakura T, Harris RA. Effects of gaseous anesthetics nitrous oxide and xenon on ligand-gated ion channels. Comparison with isoflurane and ethanol. Anesthesiology 2000; 93: 1095-101.

41. Moore NN, Bostwick JM. Ketamine dependence in anesthesia providers. Psychosomatics 1999; 40: 356-9.

42. Goyal S, Ambekar A, Ray $R$. Ketamine dependence in an anesthesiologist: an occupational hazard? Indian J Psychol Med 2014; 36: 335-7.

43. Bozimowski $G$, Groh $C$, Rouen P, Dosch $M$. The prevalence and patterns of substance abuse among nurse anesthesia students. AANA J 2014; 82: 277-83.

44. Menk EJ, Baumgarten RK, Kingsley CP, Culling RD, Middaugh $R$. Success of reentry into anesthesiology training programs by residents with a history of substance abuse. JAMA 1990; 263: 3060-2.

45. Hamza H, Bryson EO. Exposure of anesthesia providers in recovery from substance abuse to potential triggering agents. J Clin Anesth 2011; 23: 552-7.

46. Mion $G$, Villevieille $T$. Ketamine pharmacology: an update (pharmacodynamics and molecular aspects, recent findings). CNS Neurosci Ther 2013; 19: 370-80. 
47. Cheong SH, Lee KM, Lim SH, et al. Brief report: the effect of suggestion on unpleasant dreams induced by ketamine administration. Anesth Analg 2011; 112: 1082-5.

48. Moretti RJ, Hassan SZ, Goodman LI, Meltzer HY. Comparison of ketamine and thiopental in healthy volunteers: effects on mental status, mood, and personality. Anesth Analg 1984; 63: 1087-96.

49. Hocking G, Cousins MJ. Ketamine in chronic pain management: an evidence-based review. Anesth Analg 2003; 97: 1730-9.

50. Morgan CJ, Curran HV, Independent Scientific Committee on Drugs. Ketamine use: a review. Addiction 2012; 107: 27-38.

51. $\mathrm{Ng} \mathrm{SH}$, Tse $\mathrm{ML}, \mathrm{Ng} H W$, Lau FL. Emergency department presentation of ketamine abusers in Hong Kong: a review of 233 cases. Hong Kong Med J 2010; 16: 6-11.

52. Morgan CJ, Muetzelfeldt L, Curran HV. Consequences of chronic ketamine self-administration upon neurocognitive function and psychological wellbeing: a 1-year longitudinal study. Addiction 2010; 105: 121-33.

53. Wang $C$, Zheng $D, X u J$, Lam W, Yew DT. Brain damages in ketamine addicts as revealed by magnetic resonance imaging. Front Neuroanat 2013; 7: 23.

54. Featherstone RE, Liang Y, Saunders JA, Tatard-Leitman VM, Ehrlichman RS, Siegel SJ. Subchronic ketamine treatment leads to permanent changes in EEG, cognition and the astrocytic glutamate transporter EAAT2 in mice. Neurobiol Dis 2012; 47: 338-46.

55. Hollister LE, Motzenbecker FP, Degan RO. Withdrawal reactions to chlordiazepoxide ('Librium'). Psychopharmacologia 1961; 2: 63-9.

56. Lutsky I, Hopwood M, Abram SE, Cerletty JM, Hoffman RG, Kampine JP. Use of psychoactive substances in three medical specialties: anaesthesia, medicine and surgery. Can J Anaesth 1994; 41: 561-7.

57. Fry RA, Fry LE, Weeks A. Substance use disorder amongst Australian and New Zealand anaesthetic trainees: an analysis of 30 years of data. Anaesth Intensive Care 2015; 43: 530.

58. Bell DM, McDonough JP, Ellison JS, Fitzhugh EC. Controlled drug misuse by Certified Registered Nurse Anesthetists. AANA J 1999; 67: 133-40.

59. Luck $S$, Hedrick $J$. The alarming trend of substance abuse in anesthesia providers. J Perianesth Nurs 2004; 19: 308-11.

60. Tetzlaff J, Collins GB, Brown DL, Leak BC, Pollock G, Popa D. A strategy to prevent substance abuse in an academic anesthesiology department. J Clin Anesth 2010; 22: 143-50.

61. Rose GL, Brown RE Jr. The impaired anesthesiologist: not just about drugs and alcohol anymore. J Clin Anesth 2010; 22: 379-84.

62. May JA, Warltier DC, Pagel PS. Attitudes of anesthesiologists about addiction and its treatment: a survey of Illinois and Wisconsin members of the American Society of Anesthesiologists. J Clin Anesth 2002; 14: 284-9.

63. Berge KH, Dillon KR, Sikkink KM, Taylor TK, Lanier WL. Diversion of drugs within health care facilities, a multiple-victim crime: patterns of diversion, scope, consequences, detection, and prevention. Mayo Clin Proc 2012; 87: 674-82.

64. Epstein RH, Gratch DM, McNulty S, Grunwald Z. Validation of a system to detect scheduled drug diversion by anesthesia care providers. Anesth Analg 2011; 113: 160-4.

65. Epstein RH, Gratch DM, Grunwald Z. Development of a scheduled drug diversion surveillance system based on an analysis of atypical drug transactions. Anesth Analg 2007; 105: 1053-60.

66. Devine B, Gutierrez, $K$, Rogers $R$. Drug diversion by anesthesiologists: identification through intensive auditing. Am J Health Syst Pharm 2012. DOI:10.2146/ajhp120010.
67. Klein RL, Stevens WC, Kingston HG. Controlled substance dispensing and accountability in United States anesthesiology residency programs. Anesthesiology 1992; 77: 806-11.

68. Berge KH, Seppala MD, Lanier WL. The anesthesiology community's approach to opioid- and anesthetic-abusing personnel: time to change course. Anesthesiology 2008; 109: $762-4$.

69. Fitzsimons $M G$, Ishizawa $Y$, Baker $K H$. Drug testing physicians for substances of abuse: case report of a false-positive result. $J$ Clin Anesth 2013; 25: 669-71.

70. Fitzsimons $M G$, Baker KH, Lowenstein E, Zapol WM. Random drug testing to reduce the incidence of addiction in anesthesia residents: preliminary results from one program. Anesth Analg 2008; 107: 630-5.

71. Bryson EO, Silverstein JH. Addiction and substance abuse in anesthesiology. Anesthesiology 2008; 109: 905-17.

72. Kintz $P$, Villain $M$, Dumestre $V$, Cirimele $V$. Evidence of addiction by anesthesiologists as documented by hair analysis. Forensic Sci Int 2005; 153: 81-4.

73. Brock $M F$, Roy RC. Random urine drug testing. Anesth Analg 2009; 108: 676; author reply 676-7.

74. Spiegelman WG, Saunders L, Mazze RI. Addiction and anesthesiology. Anesthesiology 1984; 60: 335-41.

75. Skipper GE, Campbell MD, Dupont RL. Anesthesiologists with substance use disorders: a 5-year outcome study from 16 state physician health programs. Anesth Analg 2009; 109: 891-6.

76. Monroe T, Hamza H, Stocks G, Scimeca PD, Cowan R. The misuse and abuse of propofol. Subst Use Misuse 2011; 46: 1199205.

77. Oreskovich MR, Caldeiro RM. Anesthesiologists recovering from chemical dependency: can they safely return to the operating room? Mayo Clin Proc 2009; 84: 576-80.

78. Palhares-Alves HN, Vieira DL, Laranjeira RR, Vieira JE, Nogueira-Martins LA. Clinical and demographic profile of anesthesiologists using alcohol and other drugs under treatment in a pioneering program in Brazil. Rev Bras Anestesiol 2012; 62: 356-64.

79. Sivarajan M, Posner KL, Caplan RA, Gild WM, Cheney FW. Substance abuse among anesthesiologists. Anesthesiology 1994; 80: 704.

80. Berry CB, Crome IB, Plant $M$, Plant $M$. Substance misuse amongst anaesthetists in the United Kingdom and Ireland. The results of a study commissioned by the Association of Anaesthetists of Great Britain and Ireland. Anaesthesia 2000; 55: $946-52$.

81. Gravenstein JS, Kory WP, Marks RG. Drug abuse by anesthesia personnel. Anesth Analg 1983; 62: 467-72.

82. Weeks AM, Buckland MR, Morgan EB, Myles PS. Chemical dependence in anaesthetic registrars in Australia and New Zealand. Anaesth Intensive Care 1993; 21: 151-5.

83. Saunders D. Substance abuse and dependence in anaesthetists. Best Pract Res Clin Anaesthesiol 2006; 20: 637-43.

84. Alexander BH, Checkoway H, Nagahama SI, Domino KB. Causespecific mortality risks of anesthesiologists. Anesthesiology 2000; 93: 922-30.

85. Berge KH, Seppala MD, Schipper AM. Chemical dependency and the physician. Mayo Clin Proc 2009; 84: 625-31.

86. Warner DO, Berge K, Sun H, Harman A, Hanson A, Schroeder $D R$. Risk and outcomes of substance use disorder among anesthesiology residents: a matched cohort analysis. Anesthesiology 2015; 123: 929-36.

87. Collins GB, McAllister MS, Jensen M, Gooden TA. Chemical dependency treatment outcomes of residents in anesthesiology: results of a survey. Anesth Analg 2005; 101: 1457-62. 
88. Bryson EO, Levine A. One approach to the return to residency for anesthesia residents recovering from opioid addiction. J Clin Anesth 2008; 20: 397-400.

89. Bryson EO. Should anesthesia residents with a history of substance abuse be allowed to continue training in clinical anesthesia? The results of a survey of anesthesia residency program directors. J Clin Anesth 2009; 21: 508-13.
90. McClintock JC, Gravlee GP. Predicting success on the certification examinations of the American Board of Anesthesiology. Anesthesiology 2010; 112: 212-9.

91. Farley WJ, Talbott GD. Anesthesiology and addiction. Anesth Analg 1983; 62: 465-6. 